\title{
Pitfalls in the Diagnosis and Therapy of Infections in Elderly Patients - A Mini-Review
}

\author{
Rosa Bellmann-Weiler Günter Weiss \\ Department of Internal Medicine I, Clinical Immunology and Infectious Diseases, Innsbruck Medical University, \\ Innsbruck, Austria
}

\section{Key Words}

Infections in elderly patients · Immunity,

immunosenescence $\cdot$ Antibiotics

\begin{abstract}
Extended life expectancy is paralleled by an increasing number of patients older than 65 years suffering from severe infections. Infections in this group of patients are generally more severe and associated with an increased risk of death. This is related to several factors which are discussed in this review. Specifically, immunosenescence and an atypical presentation of infection-associated symptoms with a subsequent delay of diagnosis and initiation of antimicrobial treatment are cornerstones in this dilemma. In addition, comorbidities and comedications, a changing spectrum of pathogens with a higher percentage of multiresistant pathogens, and more importantly, an altered pharmacokinetics of antimicrobial drugs are further contributing factors to the adverse outcome of infections in elderly subjects. Infections in the elderly demand special attention in terms of diagnosis and treatment. As the mortality rates are high, special emphasis must be put on preventive measures including effective vaccination strategies and establishment of hygiene standards to prevent transmission of multiresistant pathogens among elderly patients, both in health care centers and nursing homes.

Copyright @ 2009 S. Karger AG, Basel
\end{abstract}

\section{Epidemiology and Risk of Infection in Elderly Patients}

The average life expectancy in developed countries has increased over the second half of the 20th century, and geriatric infectious diseases have thus become a health care issue of increasing importance. Infections are a major cause of death in elderly people, and they are a challenge for the practicing physician. One of the most frequent life-threatening infections is community-acquired pneumonia (CAP). The incidence of CAP is on average 4 times higher in elderly than in younger people and increases stepwise with every decade, resulting in yearly incidence rates of $1.82 \%$ in patients aged from 65 to 69 years and $5.99 \%$ in patients above 90 years [1]. In parallel, the rate of hospitalization for CAP increases with age and is 5.4-fold higher in patients above 85 years as compared to subjects between 65-74 years [1]. Risk factors are not only advanced age, but also age-related alterations of immune reactions and associated comorbidities such as chronic obstructive pulmonary disease, congestive heart failure, diabetes or current smoking. The mortality rate for CAP in elderly subjects goes up to $30 \%$ and is thus 3 times as high as in younger persons, and even $57 \%$ in elderly patients with health care-acquired pneumonia [2].

\section{KARGER}

Fax +41613061234

E-Mail karger@karger.ch

www.karger.com (c) 2009 S. Karger AG, Basel

0304-324X/09/0553-0241\$26.00/0

Accessible online at:

www.karger.com/ger
Günter Weiss, MD

Medical University, Department of Internal Medicine I

Clinical Immunology and Infectious Diseases

Anichstrasse 35, AT-6020 Innsbruck (Austria)

Tel. +43512 504 23255, Fax +43512504 25607, E-Mail guenter.weiss@i-med.ac.at 
The high CAP-associated mortality rates in elderly subjects have been partly referred to as a seasonal coincidence with influenza virus circulation. This was convincingly shown by Jackson et al. [1], who found by studying the records of more than 122,000 elderly patients that the seasonal pattern of CAP closely mirrored the percentage of death attributed to pneumonia and influenza. Accordingly, in a cohort of more than 24,000 people, all-cause mortality in unvaccinated members was strongly associated with an index of influenza circulating in the population (mortality ratio: 1.16; 95\% CI: 1.04-1.29) as compared to vaccinated controls [3]. In contrast, mortality in vaccinated people was not associated with the overall influenza activity. Thus, the increased risk of excess winter deaths seems to be widely distributed in aged people rather than being due to social status or other environmental disadvantages. Only female sex and a history of respiratory illness were identified to contribute to an increased vulnerability to CAP in this population [4]. Moreover, the risk for CAP in elderly persons is also linked to the mental status of the subjects, as patients with reduced habitual physical activity and depression suffer more frequently from respiratory tract infections as compared to age-matched cohorts [5].

Prospective studies with residents of long-term care facilities report an incidence of symptomatic urinary infections that varies from 0.1 to 2.4 cases per 1,000 resident-days. The wide variation reflects differences in patient populations among institutions and variability in surveillance definitions. Urinary tract infections are the most common infectious complication in residents of long-term care facilities [6]. Moreover, the frequency of asymptomatic urinary tract infection or asymptomatic bacteriuria among residents of long-term care facilities is remarkably high. Repeated prevalence surveys in different facilities and countries consistently report that 15 $30 \%$ of men and $25-50 \%$ of women have detectable bacteria or fungi in urine cultures. The incidence of new episodes of asymptomatic bacteriuria is 45 cases per 100 patient-years for men, and $10 \%$ of the previously nonbacteriuric men acquire bacteriuria within 3 months. Among previously bacteriuric women, the incidence of acquisition of either symptomatic or asymptomatic new infections is $0.87-1.67$ cases per patient-year, the yearly incidence of urinary tract infections increases to $50 \%$ in women above 80 years of age [7].

\section{Factors Contributing to an Increased Incidence of Infections in Elderly Patients}

Infections in the elderly are not only more frequent and more severe, but they also have distinct features concerning clinical presentation, laboratory results or microbial epidemiology. Reasons for the increased susceptibility of elderly patients to infections include epidemiological factors, the aging of the immune system/immunosenescence, malnutrition as well as a large number of age-associated physiological and anatomical alterations [8]. Moreover, the high mortality rate of infections in aged people is also partly due to late diagnosis and protracted therapeutic intervention, both of which are certainly supported by indolence of the elderly concerning their complaints.

People above 65 years of age are more likely to present with diseases aggravating the susceptibility for infections such as diabetes mellitus, chronic obstructive lung disease, heart insufficiency, renal failure, tumors or chronic infections [9]. While patients with diabetes have an increased susceptibility to infections not only because of poor vascularization and an impaired recognition of tissue damage ('diabetic foot') due to diabetic neuropathy, most importantly, these patients suffer from an impaired immune function as best reflected in delayed phagocytosis and clearance of bacteria and yeast by neutrophil granulocytes [10]. Similar observations were made in patients with chronic renal failure; however, increased urea concentrations may impair immune cell proliferation, while iron overload frequently seen in these patients negatively affects cellular immune effector function $[11,12]$. In addition, chronic liver failure results in impaired complement formation and immune cell proliferation with subsequent impaired clearance and containment of invading pathogens. Thus, comorbidities and their accompanying immune disturbances play a major role for the increased incidence and severity of infections in elderly patients.

In addition, the 'physiologic' aging of the immune system, referred to as 'immunosenescence', not only increases the incidence of infections but also of other diseases which further impact on the susceptibility towards infections, such as malignancies and autoimmune diseases $[13,14]$. The natural course of these age-related changes has not been fully elucidated so far, but specific screening procedures, such as the SENIEUR protocol, which excluded subjects showing evidence of chronic disease or patients taking medications on a regular basis $(90 \%$ of subjects, $\geq 65$ years), helped to better characterize these 
age-related changes of the immune system [15]. They found that monoclonal gammopathies and autoantibodies increased with ageing. Furthermore, there appears to be a reduced proliferative response of hematopoietic stem cells with age, which may be associated with an impaired functional activity of immune cells [16]. Specifically, the relative distribution of T-cells is significantly altered, which has in part been linked to thymic involution. In addition, chronic viral infections may further alter the T-cell balance with an expansion of CD4+ cells [17]. Accordingly, in elderly patients, a low-grade proinflammatory state is frequently found even in the absence of a known chronic disease. This may relate to the occurrence of atherosclerosis $[18,19]$ or to the reactivation of chronic viral infections on the basis of an impaired immunological control as observed for cytomegalovirus infection [17]. Nonetheless, this chronic proinflammatory state, as reflected in increased circulating concentrations of IL-6, TNF- $\alpha$ or C-reactive protein, is supposed to cause a certain degree of immune-paralysis due to downregulation of proinflammatory effector pathways [20, 21]. Accordingly, the balance between pro- and anti-inflammatory cytokines in the circulation is suggested to be a major determinant which indicates frailty and mortality in older individuals $[14,22]$. Recently, the term 'inflammaging' has been coined. This relates to a condition of a chronic inflammatory state found in elderly subjects, which may result from repetitive exposure to antigens including chronic persisting viruses, such as cytomegalovirus. Chronic immune activation results in the stimulation of counterbalancing anti-inflammatory pathways and will thus lead to a certain degree of immune paralysis exemplified by a delayed acute phase response after pathogen challenge [23].

In addition, the ageing immune system is characterized by decreased B-cell numbers, reduced production of antibodies in response to antigen exposures and by the formation of antibodies with low antigen-binding affinity and specificity. This is also a reason why elderly patients respond to vaccination less favorably, thus achieving lower levels of protection than younger subjects [14, 24]. In addition, the immune function is also affected by age-related changes in circulating concentrations of regulatory hormones such as corticosteroids and thyroid hormones. As an example, decreased serum levels of thyroid hormone in elderly patients were linked to low natural killer cell activity and thus to an impaired control of invading microorganisms [25].

More importantly, increased susceptibility to infections in elderly is also based on age-associated physio-
Table 1. Associations of immune dysfunctions with selected chronic diseases

\begin{tabular}{ll}
\hline Comorbidity & Immune dysfunction \\
\hline Diabetes mellitus & $\begin{array}{l}\text { impaired wound healing, defect in neu- } \\
\text { trophil function/opsonization of bacteria }\end{array}$ \\
\hline Hepatic failure & $\begin{array}{l}\text { lack of complement components, } \\
\text { decreased proliferation of cells of the } \\
\text { immune system }\end{array}$ \\
\hline Renal function & $\begin{array}{l}\text { defect in neutrophil function, chronically } \\
\text { decreased proliferation of cells of the } \\
\text { immune system, iron overload }\end{array}$ \\
\hline Tumors & $\begin{array}{l}\text { lack of immunoglobulin G, defects of } \\
\text { cellular immune function }\end{array}$ \\
\hline $\begin{array}{l}\text { Chronic infections } \\
\text { (HIV, HCV, HBV) }\end{array}$ & $\begin{array}{l}\text { chronic immune activation } \\
\text { Autoimmune } \\
\text { diseases }\end{array}$ \\
\hline
\end{tabular}

logical and anatomical alterations and higher frequency of comorbidities and underlying disorders with associated impaired immune responses and an associated increased risk of infections (table 1). Reduction of the ciliary motility in the trachea, for example, reduces the clearance of infectious particles and contributes to an increased risk of infections, especially in smokers or exsmokers [8]. Moreover, regurgitation and an impaired swallowing reflex on the basis of neurodegenerative disorders or stroke lead to a dramatic increase in the risk of aspiration pneumonia. More importantly, many elderly patients are malnourished and dehydrated, 2 major risk factors of infections. A recent study categorized $10-20 \%$ of nursery home inhabitants in industrialized countries and up to $50 \%$ of hospitalized persons as being malnourished $[26,27]$. Thus, it is important to correctly assess the nutritional status of nursing home residents and patients, because there is a direct link between weight loss, general illness and death in this population. Measurement of the body composition parameters fat mass, fat-free mass and total body water allows to estimate the nutritional status. As will be described below, this is also of major importance for the pharmacokinetics of anti-infective drugs in elderly patients. Unlike stable chronic diseases in older residents living in nursing homes, acute infections and recurrent hospitalizations resulted in the expansion of the underweight population group (38 vs. $11.2 \%$ ) [28]. 


\section{Pitfalls in the Diagnosis of Acute Infections in Elderly Patients}

The diagnosis of infections in elderly subjects is hampered by the atypical presentation and frequent lack of classical symptoms of infections, such as fever, rush or localized pain. Frequently, unexplained alterations of behavior, sudden confusion, perception disorders, psychomotoric agitation or lethargy, loss of appetite, dehydration, dizziness, falls and incontinence as well as tachypnea, palpitations, tachycardia, sudden heart failure or focal neurological deficits can be the only indicators of even life-threatening infections [29].

Investigation of the most frequent signs of pneumonia in elderly patients revealed general weakness, falls, perception disorders and gastrointestinal discomfort as common infection-related symptoms. No fever was reported in $20-50 \%$ of elderly patients with infections, and $10 \%$ of the patients reported no symptoms [30]. Accordingly, fever was absent ('the older the colder') in about one third of patients older than 65 years with acute, lifethreatening infections [31], and the lack of fever was associated with a poor prognosis. The reasons for this are multiple. Daily variations in body temperature are reduced, and the basic temperature is between 0.6 and $0.8^{\circ} \mathrm{C}$ lower in elderly subjects than in young adults [32]. The underlying mechanisms are: diminished production of cytokines (e.g. IL-1), reduced sensitivity of hypothalamic receptors for cytokines and impaired adaptation of peripheral thermoregulation to changes in temperature. In addition, regularly taken comedications such as nonsteroidal antirheumatics, corticosteroids, $\beta$-receptor blockers or antihistaminic drugs as well as ranitidine further suppress the febrile response to inflammation. Thus, the relative change of body temperature from baseline rather than the absolute fever peak is an indicator of infection in elderly patients. Accordingly, elevation of body temperature of more than $1.5^{\circ} \mathrm{C}$ over the baseline temperature can be interpreted as a febrile reaction and as an indicator of infection. However, it has also to be kept in mind that the method of fever measurement is important. Darowski et al. [33] found that rectal and proximal auditory temperature measurement can each detect fever in approximately $86 \%$ of febrile patients, sublingual measurement in $66 \%$ and axillary measurement only in $32 \%$ of febrile patients. Rectal temperature is clinically the most useful temperature measurement in elderly patients. In patients living in a warm environment (e.g. overheated rooms), fever often remains undetected by sublingual temperature measurement $[33,34]$. The use of a threshold of $37.5^{\circ} \mathrm{C}$ for ear measurement has comparable sensitivity and specificity for predicting fever as compared to rectal measurement [35]. More importantly, the development of a febrile reaction is also linked to the nutritional status of patients. Malnutrition leads to an impaired febrile reaction and is associated with increased infectionrelated mortality [26]. In addition, malnutrition in hospitalized patients is directly related to an increased risk for acquiring nosocomial infections [27].

As with the febrile reaction, 'classical' laboratory indicators of infection, such as C-reactive protein concentrations or leukocyte counts, have reduced sensitivity and specificity to indicate an infection in elderly patients [36], which has also been referred to as 'immunosenescence' and impaired immune response in elderly subjects.

This atypical clinical presentation of infections together with the lack of fever results in delayed diagnosis and thus in delayed onset of treatment in elderly patients. This is likewise a central factor contributing to increased mortality in elderly patients, as it is well known that mortality from severe infections is directly associated with the timing of initial therapy leading from 8 - to 22 -fold higher mortality rates of severe infections when empirical therapy is delayed by $8-24 \mathrm{~h} \mathrm{[37].}$

\section{Specific Considerations for Antibiotic Therapy in Elderly Patients}

The initial treatment of an infection is almost always empirically based. One has to be well aware of the most frequent pathogens underlying a specific infection, their antimicrobial susceptibility and the local pattern of antimicrobial resistances. While elderly patients who live at home and have not been admitted to hospital over the past year have a spectrum of pathogens for specific infections (e.g. pneumonia) which is comparable to young adults, this pattern can be completely different in nursing home residents or patients who have recently been admitted to hospital. In this latter group, a higher percentage of 'nosocomial' bacteria and resistant pathogens including methicillin-resistant Staphylococcus aureus or resistant Gram-negative rods has to be anticipated [38].

Although empirical therapy is mandatory, it is essential to obtain specimen for microbiological analyses (e.g. blood culture, urine culture) before antimicrobial therapy can be initiated. This treatment regimen may be adapted according to the results of these cultures if the patient has not responded clinically to the initial therapy. However, the results of microbiological tests have to be inter- 
Table 2. Changes of the physiological functions in elderly subjects and their impact on pharmacokinetics

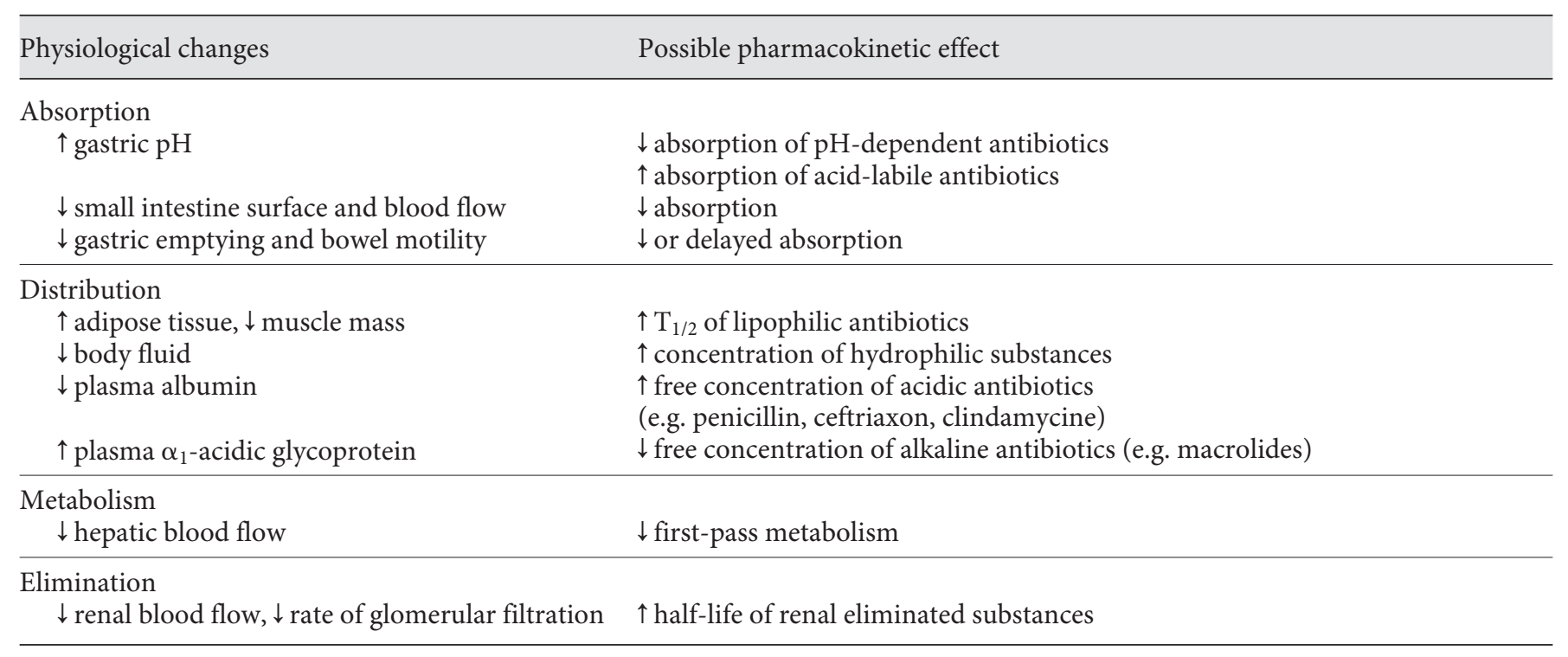

preted in context with the clinical presentation of the patient, and thus not every positive culture result is an indicator for treatment. To give an example, asymptomatic bacteriuria does not require antibiotic therapy; moreover, antimicrobial therapy may result in adverse side effects $[6,7]$.

Again, to select the appropriate empirical therapy knowledge of the local epidemiology in terms of likely pathogens and their resistance patterns as well as the physician's clinical experience are absolutely essential [37]. An important decision is whether patients can be safely treated at home or must be admitted to hospital. For patients with pneumonia, the Pneumonia Severity Index (PSI) score [39] or the CRB-65 or CURB-65 (Confusion, Urea, Respiratory rate, Blood pressure, age 65 or older) index [40] have been introduced in clinical practice to help physicians take this clinical decision.

When selecting antimicrobial drugs for elderly patients, it has to be acknowledged that, in general, all drugs can be used for the same indications as in young patients. However, dosages and intervals of drug application have to be adapted in elderly patients with low body weight (or body mass index) and reduced renal function, and contraindications may be more frequent in elderly patients due to comedications or underlying organ dysfunctions [41]. In addition, adverse drug reactions occur 2-3 times more frequently in aged subjects than in patients of younger age [42]. In a Belgian study, the incidence of adverse drug reactions in elderly patients was estimated to be around 20\% in hospitalized patients, while in another study, the side effects of comedications were the cause for hospitalization in up to $10 \%$ of admissions [43]. The risk for adverse drug reactions and interactions increases with the number of medications taken, and this number is obviously higher in elderly subjects [44].

Changes in body tissue composition with age result in an altered volume of distribution for drugs. This is of importance for the efficacy of both hydrophilic and hydrophobic antimicrobial substances. With advanced age, the relative percentage of body water decreases, resulting in a reduced volume of distribution for hydrophilic substances and thus in higher circulating concentrations of such drugs. In contrast, the relative increase of adipose tissue with age leads to a higher distribution volume for lipophilic drugs, thus resulting in lower tissue concentrations and a prolonged half-life of those drugs. In addition, reduced circulating concentrations of albumin in elderly patients affect the protein-binding capacity for drugs and thereby the ratio between the bound and free/unbound fraction of antibiotics [45].

Changes in gastric $\mathrm{pH}$, intestinal motility and intestinal enzymatic activity also affect the bioavailability and absorption of antibiotics (table 2). Age-related reduction of the liver and renal function then impact on the half-life of these drugs. Specifically, an age-related reduction of the liver function and metabolic activity results in a reduced first-pass effect and altered half-life of drugs which are metabolized within this organ. This is of importance 
Table 3. Some important drug interactions of antibiotics

\begin{tabular}{|c|c|c|}
\hline Drug & Adverse drug reaction & Antibiotic \\
\hline Marcumar & higher risk of bleeding & $\begin{array}{l}\text { aminopenicillin } \\
\text { cephalosporins } \\
\text { metronidazol } \\
\text { erythromycin }\end{array}$ \\
\hline Digitalis & $\begin{array}{l}\text { enhancement of active } \\
\text { pharmaceutical ingredient }\end{array}$ & $\begin{array}{l}\text { macrolides } \\
\text { penicillins }\end{array}$ \\
\hline Antiplatelet agents & increased risk of bleeding & $\begin{array}{l}\text { cephalosporins } \\
\text { aminopenicillins }\end{array}$ \\
\hline Theophyllin & convulsion & macrolides \\
\hline $\begin{array}{l}\text { Calcium channel blockers } \\
\text { (e.g. diltiazem, verapamil) }\end{array}$ & ventricular fibrillation & $\begin{array}{l}\text { erythromycin } \\
\text { clarithromycin }\end{array}$ \\
\hline Furosemide & renal insufficiency & cephalosporins \\
\hline Selective serotonin reuptake inhibitors & serotonin syndrome & linezolid \\
\hline
\end{tabular}

for drugs with primary metabolization in the liver, such as chloramphenicol or clindamycine. Worthy of note, side effects of antibiotics such as cholestatic hepatitis or impaired liver function tests occur more frequently in elderly subjects and are observed in almost all classes of antimicrobial drugs, however, more frequently with clavulanic acid, flucloxacilline, rifampicin, macrolides or azoles [46].

Most antibiotics are eliminated via urinary excretion. The rate of glomerular filtration is physiologically restrained with advanced age. The creatinine level in serum does not correctly reflect the renal function, and thus the glomerular filtration rate has to be calculated with the Cockroft-Gould formula, and dose adaptations in patients with renal insufficiency have to be performed for most antibiotics. The formula that would take into account reduced body weight seems to be the MDRD2 formula which appears to be gold standard for the estimation of renal function, especially in elderly patients.

Moreover, antimicrobial drugs may not penetrate into tissue as easily as in young patients, thus resulting in insufficient drug concentrations at the site of infection. This is not only due to the altered distribution volume of the drug in the body, as discussed above, but is also related to impaired tissue perfusion as a consequence of chronic heart failure and peripheral arterial disease mostly as a result of atherosclerosis. This situation is further worsened in case of severe infection or septic shock. Even in young patients, tissue penetration of antibiotics at septic shock is reduced by $1-2$ logs, which may be even worse in elderly subjects [47]. Thus, even when antibiotics are applied at the recommended dosages, it is likely that for certain pathogens in specific compartments only suboptimal therapeutic drug levels are achieved. This may result in failure of therapy, although the correct antibiotic has been chosen, and although the anticipated pathogen is principally susceptible to the drug used. Unfortunately, there is hardly any evidence from prospective studies which would provide the physician with information how to dose antibiotics in septic elderly patients with/without complicating comorbidities.

Special attention has to be dedicated to drug interactions of antimicrobials with comedications regularly taken by patients. Interactions with the cytochrome P-450 system are of clinical relevance. Specifically, inhibition of the enzyme CYP3A4 causes reduced degradation of antibiotics like macrolides, azoles and, in a competitive way, also of quinolones. Vice versa, antibiotics can prolong the half-life of other drugs resulting in life-threatening side effects, some of which are listed in table 3. Induction of cytochrome enzymes, e.g. by rifampicin, reduces the half-life of comedication resulting in subtherapeutic concentrations of these drugs.

The slogan 'start low, go slow' should not be used in association with antibiotic therapy. Instead, the therapeutic principle for the treatment of infections is 'hit hard and early'. Administration of antimicrobials within $4 \mathrm{~h}$ after admission to hospital was associated with decreased 
mortality and length of stay among a random sample of older inpatients with CAP who had not received any antibiotics before [30, 48]. Kumar et al. [37] showed in patients with septic shock that each hour of delay at the beginning of antimicrobial therapy over the ensuing $6 \mathrm{~h}$ after admission was associated with an average decrease in survival of $7.6 \%$. Despite a progressive increase in mortality rate with increasing delays, only $50 \%$ of septic shock patients received effective antimicrobial therapy within $6 \mathrm{~h}$ of documented hypotension [37]. In addition, to hit hard, sufficiently high dosages of antibiotics should be administered, and several experts recommend a loading dosage of $\beta$-lactams for instance or a continuous infusion scheme to achieve sufficiently high tissue concentrations at the site of infection [49].

The use of a correct dose is not only a central determinant for the success of treatment, but also a critical point for avoiding the development of resistance. Suboptimal dosing of antibiotics leads to the emerge of resistant pathogens which cannot be treated with the initial regimen [50]. As discussed above, the choice of the correct dose of antibiotics for elderly patients may be an art, taking into account poor tissue penetration in association with septicemia, altered pharmacokinetics, accompanying diseases and impaired immune response.

Finally, not only the timing but, most importantly, the choice of the appropriate drug which is most likely to cover the expected pathogens is a critical determinant deciding about success or failure of the therapy. Several studies, e.g. in patients with nosocomial pneumonia, have demonstrated that the initial choice of the wrong antibiotic is associated with an approximately twofold increase in the mortality rate [51]. Accordingly, a prospective study in Denmark provided evidence that the probability of choosing the correct initial therapy increases with the physician's skills. Thus, patients with septicemia were more likely to receive the correct therapy and thus had an increased survival rate when the empirical therapy was selected and prescribed by an infectious diseases specialist [52].

For the selection of an empirical therapy, it may be of importance to review previous microbiological findings in patients, since some pathogens tend to reemerge. Methicillin-resistant S. aureus, for instance, very frequently reemerges even after successful antimicrobial elimination, thus causing another infection [53]. Such subjects can transmit these highly resistant pathogens to other people, which is of importance in hospitals and nursing homes. Thus, not only treatment of the infection, but also adherence to standard hygiene measures are cor- nerstones to reduce the incidence of nosocomial infections and the transmission of resistant pathogens among elderly patients in health care facilities, a measure which will also reduce all-case mortality in this group of patients [54].

As infections in elderly patients occur more frequently and are more severe, measures to prevent infections are highly desirable. Vaccination is widely recommended for patients above 65 years, although immunological responses to vaccination decrease with advanced age. However, even when no protective antibodies can be detected after vaccination, e.g. against influenza, these patients have a reduced risk for this infection as well as for complications and death associated with influenza compared to unvaccinated subjects [55]. Moreover, vaccination against influenza results in a reduction of all-case mortality in elderly patients [3]. Accordingly, similar positive effects have also been attributed to pneumococcal vaccination in this group of patients [56]. Improved vaccination strategies, new adjuvants and new vaccines that specifically target the aged immune system will help to overcome the limitations of immunosenescence and ensure better protection of the vulnerable elderly population [57]. In addition, an optimized treatment for chronic underlying diseases, such as diabetes or heart insufficiency, a good nutritional status and improved hygiene standards especially in nursing homes will help to reduce the incidence of severe infections in elderly patients, while improved diagnostic strategies and careful assessment and observation of elderly patients will help us to identify and treat infections as early as possible.

References

1 Jackson ML, Neuzil KM, Thompson WW, Shay DK, Yu O, Hanson CA, Jackson LA: The burden of community-acquired pneumonia in seniors: results of a population-based study. Clin Infect Dis 2004;39:1642-1650.

$\checkmark 2$ El-Solh AA, Sikka P, Ramadan F, Davies J: Etiology of severe pneumonia in the very elderly. Am J Respir Crit Care Med 2001;163: 645-651.

-3 Armstrong BG, Mangtani P, Fletcher A, Kovats S, McMichael A, Pattenden S, Wilkinson P: Effect of influenza vaccination on excess deaths occurring during periods of high circulation of influenza: cohort study in elderly people. BMJ 2004;329:660.

$\checkmark 4$ Wilkinson P, Pattenden S, Armstrong B, Fletcher A, Kovats RS, Mangtani P, McMichael AJ: Vulnerability to winter mortality in elderly people in Britain: population-based study. BMJ 2004;329:647. 
5 Kostka T, Praczko K: Interrelationship between physical activity, symptomatology of upper respiratory tract infections and depression in elderly people. Gerontology 2007; 53:187-193.

6 Nicolle LE: Urinary tract infection in geriatric and institutionalized patients. Curr Opin Urol 2002;12:51-55.

7 Nicolle LE, Bradley S, Colgan R, Rice JC, Schaeffer A, Hooton TM: Infectious Diseases Society of America guidelines for the diagnosis and treatment of asymptomatic bacteriuria in adults. Clin Infect Dis 2005;40: 643-654.

$\checkmark 8$ Gavazzi G, Krause KH: Ageing and infection. Lancet Infect Dis 2002;2:659-666.

-9 Esper AM, Moss M, Lewis CA, Nisbet R, Mannino DM, Martin GS: The role of infection and comorbidity: factors that influence disparities in sepsis. Crit Care Med 2006;34: 2576-2582.

10 Zykova SN, Jenssen TG, Berdal M, Olsen R, Myklebust R, Seljelid R: Altered cytokine and nitric oxide secretion in vitro by macrophages from diabetic type II-like $\mathrm{db} / \mathrm{db}$ mice. Diabetes 2000;49:1451-1458.

- 11 Weiss G, Meusburger E, Radacher G, Garimorth K, Neyer U, Mayer G: Effect of iron treatment on circulating cytokine levels in ESRD patients receiving recombinant human erythropoietin. Kidney Int 2003;64: 572-578.

12 Chonchol M: Neutrophil dysfunction and infection risk in end-stage renal disease. Semin Dial 2006;19:291-296.

13 Pawelec G: Immunosenescence: impact in the young as well as in the old? Mech Ageing Dev 1999;188:1-7.

- 14 Aw D, Silva AB, Palmer DB: Immunosenescence: emerging challenges for an ageing population. Immunology 2007;120:435-446.

- 15 Ligthart GJ, Corberand JX, Geertzen HG, Meinders AE, Knook DL, Hijmans W: Necessity of the assessment of health status in human immunogerontological studies: evaluation of the SENIEUR protocol. Mech Ageing Dev 1990;55:89-105.

16 Geiger H, Van Zant G: The aging of lymphohematopoetic stem cells. Nat Immunol 2002; 3:329-333.

17 Weinberger B, Lazuardi L, Weiskirchner I, Keller M, Neuner C, Fischer KH, Neuman B, Würzner R, Grubeck-Loebenstein B: Healthy aging and latent infection with CMV lead to distinct changes in CD8+ and CD4+ T-cell subsets in the elderly. Hum Immunol 2007; 68:86-90.

18 Mayr M, Kiechl S, Willeit J, Wick G, Xu Q: Infections, immunity and atherosclerosis: associations of antibodies to Chlamydia pneumoniae, Helicobacter pylori and cytomegalovirus with immune reactions to heatshock protein 60 and carotid or femoral atherosclerosis. Circulation 2000;102:833-839.
19 Weiss G, Willeit J, Kiechl S, Fuchs D, Jarosch E, Oberhollenzer F, Reibnegger G, Tilz GP, Gerstenbrand F, Wachter H: Increased concentrations of neopterin in carotid atherosclerosis. Atherosclerosis 1994;106:263-271.

20 Castle SC: Clinical relevance of age-related immune dysfunction. Clin Infect Dis 2000; $31: 578-585$.

21 Krabbe KS, Pedersen M, Bruunsgaard H: Inflammatory mediators in the elderly. Exp Gerontol 2004;39:687-699.

22 van den Biggelaar AH, Huizinga TW, de Craen AJ, Gussekloo J, Heijmans BT, Frölich M, Westendorp RG: Impaired innate immunity predicts frailty in old age: the Leiden 85-plus study. Exp Gerontol 2004;39:14071414.

23 Franceschi C: Inflammaging as a major characteristic of old people: can it be prevented or cured? Nut Rev 2007;65:S173S176.

24 Nicoletti C, Yang X, Cerny J: Repertoire diversity of antibody response to bacterial antigens in aged mice. III. Phosphorylcholine antibody from young and aged mice differ in structure and protective activity against infection with Streptococcus pneumoniae. J Immunol 1993;150:543-549.

25 Kmiec Z, Myśliwska J, Rachón D, Kotlarz G, Sworczak K, Myśliwski A: Natural killer activity and thyroid hormone levels in young and elderly persons. Gerontology 2001;47: 282-288.

26 Kagansky N, Berner Y, Koren-Morag N, Perelman L, Knobler H, Levy S: Poor nutritional habits are predictors of poor outcome in very old hospitalized patients. Am J Clin Nutr 2005;82:784-791.

27 Paillaud E, Herbaud S, Caillet P, Lejonc JL, Campillo B, Bories PN: Relations between undernutrition and nosocomial infections in elderly patients. Age Ageing 2005;34:619625.

28 Kimyagarov S, Shabi A, Levenkron S: Nutritional status assessment in nursing home elderly residents. Harefuah 2007;146:759-761.

29 Werner H, Kuntsche J: Infektionen im Alter - was ist anders? Z Gerontol Geriatr 2000; 33:350-356.

-30 Janssens JP, Krause KH: Pneumonia in the very old. Lancet Infect Dis 2004;4:112-124.

31 Norman DC, Grahn D, Yoshikawa TT: Fever and aging. J Am Geriatr Soc 1985;33:859863.

32 Downton JH, Andrews K, Puxty JA: 'Silent' pyrexia in the elderly. Age Ageing 1987;16: 41-44.

33 Darowski A, Najim Z, Weinberg J, Guz A: The febrile response to mild infections in elderly hospital inpatients. Age Ageing 1991; 20:193-198.

34 Darowski A, Weinberg JR, Guz A: Normal rectal, auditory canal, sublingual and axillary temperatures in elderly afebrile patients in a warm environment. Age Ageing 1991;20: 113-119.
35 Smitz S, Giagoultsis T, Dewé W, Albert A: Comparison of rectal and infrared ear temperatures in older hospital inpatients. J Am Geriatr Soc 2000;48:63-66.

36 Stucker F, Herrmann F, Graf JD, Michel JP, Krause KH, Gavazzi G: Procalcitonin and infection in elderly patients. J Am Geriatr Soc 2005;53:1392-1395.

37 Kumar A, Roberts D, Wood KE, Light B, Parrillo JE, Sharma S, Suppes R, Feinstein D, Zanotti S, Taiberg L, Gurka D, Kumar A, Cheang M: Duration of hypotension before initiation of effective antimicrobial therapy is the critical determinant of survival in human septic shock. Crit Care Med 2006;34: 1589-1596.

38 Ferrara AM, Fietta AM: New developments in antibacterial choice for lower respiratory tract infections in elderly patients. Drugs Ageing 2004;21:167-186.

-39 Fine MJ, Auble TE, Yealy DM, Hanusa BH, Weissfeld LA, Singer DE, Coley CM, Marrie TJ, Kapoor WN: A prediction rule to identify low-risk patients with community-acquired pneumonia. N Engl J Med 1997;336: 243-250.

40 Lim WS, van der Eerden MM, Laing R, Boersma WG, Karalus N, Town GI, Lewis SA, Macfarlane JT: Defining community-acquired pneumonia severity on presentation to hospital: an international derivation and validation study. Thorax 2003;58:377-382.

41 McCue JD: Antibiotic use in the elderly: issues and nonissues. Clin Infect Dis 1999;28: 750-752.

42 Veehof LJG: Adverse drug reactions and polypharmacy in the elderly in general practice. Eur J Clin Pharmacol 1999;55:533-536.

43 Pirmohamed M: Adverse drug reactions as cause of admission to hospital of $18,820 \mathrm{pa}-$ tients. BMJ 2004;329:15-19.

44 Klarin J, Wimo A, Fatsbom J: The association of inappropriate drug use with hospitalization and mortality: a population-based study of the very old. Drugs Aging 2005;22: 69-82.

\$4 Faulkner CM, Cox HL, Williamson JC: Unique aspects of antimicrobial use in older adults. Clin Infect Dis 2005;40:997-1004.

46 García Rodríguez LA, Stricker BH, Zimmerman HJ: Risk of acute liver injury associated with the combination of amoxicillin and clavulanic acid. Arch Intern Med 1996;156: 1327-1332.

47 Sauermann R, Delle-Karth G, Marsik C, Steiner I, Zeitlinger M, Mayer-Helm BX, Georgopoulos A, Müller M, Joukhadar C: Pharmacokinetics and pharmacodynamics of cefpirome in subcutaneous adipose tissue of septic patients. Antimicrob Agents Chemother 2005;49:650-655. 
48 Houck PM, Bratzler DW, Nsa W, Ma A, Bartlett JG: Timing of antibiotic administration and outcomes for Medicare patients hospitalized with community-acquired pneumonia. Arch Intern Med 2004; 164:637-644.

49 Boselli E, Breilh D, Duflo F, Saux MC, Debon R, Chassard D, Allaouchiche B: Steady-state plasma and intrapulmonary concentrations of cefepime administered in continuous infusion in critically ill patients with severe nosocomial pneumonia. Crit Care Med 2003;31:2102-2106.

50 Thomas JK, Forrest A, Bhavnani SM, Hyatt JM, Cheng A, Ballow CH, Schentag JJ: Pharmacodynamic evaluation of factors associated with the development of bacterial resistance in acutely ill patients during therapy. Antimicrob Agents Chemother 1998;42: 521-527.
1 Luna CM, Vujacich P, Niederman MS, Vay C, Gherardi C, Matera J, Jolly EC: Impact of BAL data on the therapy and outcome of ventilator-associated pneumonia. Chest 1997; 111:676-685.

52 Byl B, Clevenbergh P, Jacobs F, Struelens MJ, Zech F, Kentos A, Thys JP: Impact of infectious diseases specialists and microbiological data on the appropriateness of antimicrobial therapy for bacteremia. Clin Infect Dis 1999;29:60-66.

53 Robinson DA, Kearns AM, Holmes A, Morrison D, Grundmann H, Edwards G, O'Brien FG, Tenover FC, McDougal LK, Monk AB, Enright MC: Re-emergence of early pandemic Staphylococcus aureus as a community-acquired meticillin-resistant clone. Lancet 2005;365:1256-1258.
54 Pittet D, Hugonnet S, Harbarth S, Mourouga P, Sauvan V, Touveneau S, Perneger TV: Effectiveness of a hospital-wide programme to improve compliance with hand hygiene: infection control programme. Lancet 2001; 357:479-480.

55 Hak E, Nordin J, Wei F, Mullooly J, Poblete S, Strikas R, Nichol KL: Influence of highrisk medical conditions on the effectiveness of influenza vaccination among elderly members of 3 large managed-care organizations. Clin Infect Dis 2002;35:370-377.

56 Nichol KL, Nordin JD, Nelson DB, Mullooly JP, Hak E: Effectiveness of influenza vaccine in the community-dwelling elderly. $\mathrm{N}$ Engl J Med 2007;357:1373-1381.

57 Weinberger B, Herndler-Brandstetter D, Schwanninger A, Weiskopf D, Grubeck-Loebenstein B: Biology of immune responses to vaccines in elderly persons. Clin Infect Dis 2008;46:1078-1084. 